\title{
VISUAL AND OTHER SELECTION IN CEPAEA: A FURTHER EXAMPLE
}

\author{
J. J. D. GREENWOOD \\ Department of Biological Sciences, University of Dundee
}

Received 4.iv.73

\begin{abstract}
SUMMARY
Populations of Cepaea nemoralis and $C$. hortensis have been sampled in a small area in north-west Worcestershire. No clear ecological separation between the two species is apparent.

Morphs of $C$. nemoralis that one would expect to vary in frequency between woods and open habitats on the basis of visual selection do so in the manner expected.

The variation shown by $C$. hortensis in the region is quite different and much reduced, compared with that of $C$. nemoralis. The expected differences between woods and open habitats still occur, however. Tests for any relations between morph-frequency and two other environmental variables (altitude and proximity to water) have been made. Only altitude shows such relations: unbanded in C. hortensis tends to rise in frequency with altitude and listeria in C. nemoralis may do so.

The Index of Polymorphism of $C$. nemoralis is always high if $C$. hortensis is present, but may be low if the latter is absent. Several mechanisms which could explain this are suggested. Linkage disequilibria are apparent in $C$. nemoralis. Banding is deficient in browns and at an excess in yellows, compared with pinks, in all habitats. It is concluded that the diversity of selective forces acting affectively on Cepaea populations, not random events, is responsible for the wide variation between them in morph-frequencies.
\end{abstract}

\section{INTRODUCTION}

DURING the last quarter of a century studies of the genetic variation of Cepaea nemoralis (L.) and C. hortensis (Mull.) have shown that great differences may exist between regions in the type of variation exhibited. One method of investigating the reasons for such differences is to compare numerous regions and attempt to discover any regularities which may exist. The present study was made to add one more to the rapidly lengthening list of such regions studied in Britain. The region was chosen solely on the basis that I happened to be living there, so that the choice was random as far as the snails are concerned.

The area studied is an approximate square of side $12 \mathrm{~km}$, situated immediately south-west of Worcester $\left(52^{\circ} 12^{\prime} \mathrm{N}, 2^{\circ} 11^{\prime} \mathrm{W}\right)$. It lies some $37 \mathrm{~km}$ west of the region studied by Currey, Arnold and Carter (1964) and is ecologically similar to it. The topography is undulating, the soil being cold, damp, heavy clay. The land is well wooded and much of the area is permanent pasture, though arable farming is by no means uncommon.

The work was pursued between late summer 1964 and early summer 1966.

\section{MEthods}

Random collections of Cepaea were made within areas of less than $30 \mathrm{~m}$ diameter. Snails are not common in the region and many of the collections 
Table 1

Details of sites and of collections taken from them

\begin{tabular}{|c|c|c|c|c|c|c|}
\hline Name of site & Grid reference & Habitat & Altitude & Water & C. nemoralis & C. hortensi \\
\hline Caldewell Wood & 914483 & W & 75 & + & 7 & 2 \\
\hline Clerkenleap & 852514 & W & 50 & + & 0 & 16 \\
\hline Croome D'Abitot & 888453 & $\mathrm{RH}$ & 125 & - & 10 & 55 \\
\hline Croome Perry Wood & 903472 & W & 100 & - & 5 & 8 \\
\hline Deerfold Wood & 909478 & W & 125 & - & 19 & 1 \\
\hline Dunstall & 882431 & $\mathrm{H}$ & 50 & - & 8 & 0 \\
\hline Great Comberton & 961429 & $\mathrm{H}$ & 100 & - & 1 & 19 \\
\hline Hatfield & 868506 & $\mathbf{H}$ & 100 & - & 60 & 0 \\
\hline High Green 1 & 870457 & $\mathrm{RH}$ & 75 & - & 16 & 0 \\
\hline High Green 2 & 874457 & W & 75 & - & 17 & 0 \\
\hline Lower Wolverton & 927501 & W & 100 & + & 45 & 0 \\
\hline Normoor & 862474 & W & 75 & + & 10 & 27 \\
\hline Norton & 893514 & RH & 125 & - & 26 & 1 \\
\hline Norton 2 & 893509 & G & 125 & - & 0 & 12 \\
\hline Pershore 1 and 2 & 952449 & $\mathrm{TH}$ & 50 & + & 0 & 44 \\
\hline Pirton 1 & 892470 & $\mathrm{H}$ & 75 & - & 9 & 0 \\
\hline Pirton 2 & 888471 & $\mathrm{H}$ & 100 & - & 18 & 1 \\
\hline Pirton 3 & 880479 & $\mathrm{~W}$ & 175 & - & 7 & 0 \\
\hline Pirton Court & 881465 & $\mathrm{H}$ & 100 & - & 12 & 0 \\
\hline Spetchley 1 & 890541 & $\mathrm{~W}$ & 200 & - & 30 & 0 \\
\hline Spetchley 2 & 893541 & $\mathbf{H}$ & 200 & - & 23 & 0 \\
\hline Spetchley 3 & 900539 & W & 175 & - & 31 & 0 \\
\hline Spetchley Park 1 & 896531 & W & 150 & + & 5 & 0 \\
\hline Spetchley Park 2 & 891536 & W & 150 & + & 24 & 0 \\
\hline Stonebow & 938498 & $\mathrm{H}$ & 100 & + & 26 & 0 \\
\hline Stoulton & 909491 & W & 100 & + & 2 & 43 \\
\hline Swinesherd 1 and 2 & 879540 & W & 175 & - & 62 & 27 \\
\hline Swinesherd 3 & 886541 & G & 200 & - & 1 & 0 \\
\hline Swinesherd 4 & 886541 & W & 200 & - & 3 & 0 \\
\hline Swinesherd 5 & 886541 & W & 200 & - & 13 & 0 \\
\hline Swinesherd 6 & 877540 & $\mathbf{H}$ & 175 & - & 48 & 34 \\
\hline Tiddesley Wood & 930444 & W & 100 & + & 11 & 4 \\
\hline Wadborough & 913480 & $\mathrm{H}$ & 100 & + & 2 & 1 \\
\hline Whittington & 878522 & $\mathrm{H}$ & 175 & - & 19 & 0 \\
\hline Worcester 1 & 868535 & $\mathrm{H}$ & 150 & - & 7 & 0 \\
\hline Worcester 2 & 868530 & G & 150 & + & 3 & 0 \\
\hline Worcester 3 & 866528 & $\mathrm{RH}$ & 100 & + & 9 & 0 \\
\hline Worcester 4 & 866528 & $\mathrm{RH}$ & 100 & + & 22 & 0 \\
\hline Worcester 5 & 869522 & $\mathrm{RH}$ & 125 & - & 23 & 0 \\
\hline Worcester 6 & 868539 & $\mathrm{H}$ & 100 & + & 1 & 0 \\
\hline Worcester 7 & 874541 & $\mathbf{H}$ & 200 & - & 33 & 0 \\
\hline Worcester 8 & 875540 & $\mathrm{RH}$ & 175 & + & 1 & 106 \\
\hline Worcester 9 & 866538 & G & 200 & - & 1 & 0 \\
\hline Worcester 10 & 865541 & $\mathrm{RH}$ & 225 & - & 36 & 0 \\
\hline
\end{tabular}

Notes

1. Grid reference. Six-figure reference on the National Grid. All sites fall in the 100-km. square $\mathrm{SO}$,

2. Habitat. $\mathrm{W}=$ Wood. $\mathbf{H}=$ Hedge. $\mathrm{TH}=$ Tall herbage. $\mathrm{RH}=$ Rough herbage. $\mathrm{G}=$ Grassland. For further explanation see text.

3. Altitude. In feet above mean sea-level; to the nearest 25 feet.

4. Water. $+=$ Near water. $-=$ Not near water. For further explanation see text.

5. Columns headed " $C$. nemoralis" and " $C$. hortensis" give the total numbers of each species found.

6. Remaining columns give the number of shells of each morph taken at each site, blank indicating none. $0=$ Unbanded. $3=$ Mid-banded. $\mathrm{L}=$ Listeria (00345). $5=$ Five-banded and its minor modifications. UF $=$ Shells with fusions involving the upper bands. $\mathrm{LF}=$ Shells with fusions involving the lower bands. $\mathrm{FB}=$ Banded, not hyalozonate. HY = Hyalozonate banded. 
TABLE 1 (continued)

C. nemoralis

\begin{tabular}{|c|c|c|c|c|c|c|c|c|c|c|c|c|c|c|c|c|c|c|c|c|}
\hline & & Yello & & & & & & ink & & & & & Bro & wn & & & & horten & & \\
\hline 0 & $\begin{array}{ll}3 & I \\
1 & \end{array}$ & L $\quad 5$ & UF & $\mathbf{L F}$ & $\begin{array}{l}0 \\
2\end{array}$ & $\begin{array}{l}3 \\
2\end{array}$ & L & $\begin{array}{l}5 \\
1\end{array}$ & $\begin{array}{c}\mathrm{UF} \\
1\end{array}$ & $\underset{1}{\mathrm{LF}}$ & $\begin{array}{l}0 \\
1\end{array}$ & 3 & L 5 & $5 \mathrm{UF}$ & LF & $\begin{array}{c}0 \\
1\end{array}$ & $\begin{array}{c}\text { FB } \\
1\end{array}$ & & UF & LF \\
\hline & & & & & & & & & & & & & & & & 7 & 9 & & 6 & 6 \\
\hline & & 1 & & & & 1 & 2 & 3 & & & 3 & & & & & 33 & 21 & 1 & 3 & 1 \\
\hline & & & & & & 1 & 1 & 3 & 1 & 1 & & & & & & 2 & 6 & & 2 & \\
\hline 1 & 2 & & & & 1 & 6 & 2 & 2 & 1 & 1 & 5 & & & & & 1 & & & & \\
\hline & & 2 & 1 & 1 & & & & 5 & 1 & 3 & 1 & & & & & & & & & \\
\hline & & & & & & & & 1 & 1 & 1 & & & & & & 3 & 16 & & 4 & 4 \\
\hline & 2 & 11 & 8 & 8 & & 11 & & $\begin{array}{l}23 \\
10\end{array}$ & $\begin{array}{l}9 \\
4\end{array}$ & $\begin{array}{r}10 \\
5\end{array}$ & $\begin{array}{l}6 \\
2\end{array}$ & & 1 & & & & & & & \\
\hline & & 1 & 1 & 1 & & 1 & 3 & 11 & 9 & 12 & 1 & & & & & & & & & \\
\hline 4 & & 6 & 3 & 3 & 2 & 1 & 3 & 7 & 3 & 5 & 18 & & 1 & & & & & & & \\
\hline & 2 & 1 & 1 & & 1 & 3 & & 2 & & 1 & 1 & & & & & 14 & 13 & & 5 & 5 \\
\hline & 6 & 111 & 3 & 2 & & 2 & & 4 & 3 & 3 & 2 & & & & & & 1 & & & \\
\hline & & & & & & & & & & & & & & & & 2 & 10 & & 1 & \\
\hline & & & & & & & & & & & & & & & & 19 & 25 & & 5 & 8 \\
\hline & 1 & 4 & 3 & 3 & & & 1 & 2 & 1 & 1 & & & & & & & & & & \\
\hline & 6 & 6 & 4 & 3 & & 1 & 1 & 2 & 2 & 1 & 2 & & & & & 1 & & & & \\
\hline 1 & 1 & & & & & 1 & & 3 & 1 & 1 & 2 & & & & & & & & & \\
\hline & 1 & 1 & 1 & 2 & & $\begin{array}{l}1 \\
3\end{array}$ & 1 & $\begin{array}{r}6 \\
16\end{array}$ & $\begin{array}{l}4 \\
5\end{array}$ & $\begin{array}{l}5 \\
4\end{array}$ & 1 & & 1 & & & & & & & \\
\hline & 1 & 5 & 3 & 2 & 4 & 4 & 2 & $\begin{array}{r}10 \\
4\end{array}$ & $\begin{array}{l}3 \\
2\end{array}$ & 2 & & & & & & & & & & \\
\hline & 1 & 3 & 1 & 1 & 2 & 11 & 3 & 9 & 7 & 10 & 1 & & & & & & & & & \\
\hline & 2 & & & & & & & 3 & 2 & & & & & & & & & & & \\
\hline & 6 & & & & 1 & 9 & 2 & 1 & & 2 & 5 & & & & & & & & & \\
\hline & 3 & 9 & 3 & 3 & & 1 & 3 & 4 & 2 & 1 & 3 & 1 & & & & & & & & \\
\hline & & & & & & 1 & & 1 & 1 & & & & & & & 18 & 25 & 1 & 10 & 13 \\
\hline & 10 & 7 & 2 & 2 & 12 & 3 & 10 & 9 & 3 & 6 & 9 & 2 & & & & 19 & 8 & & 2 & 2 \\
\hline & & & & & 3 & & & & & & & & & & & & & & & \\
\hline & & & & & 7 & 2 & 1 & 2 & 2 & 2 & 1 & & & & & & & & & \\
\hline & 2 & 510 & 3 & 6 & 1 & 4 & 7 & 16 & 7 & 17 & 3 & & & & & 25 & 9 & & 1 & 5 \\
\hline & & 1 & & 1 & 1 & 2 & 2 & 1 & & & 2 & 1 & 1 & & & 2 & 2 & & 1 & \\
\hline & 1 & 1 & & & & & & & & & & & & & & & 1 & & & \\
\hline & 3 & 7 & 3 & 4 & & 6 & & 3 & 2 & 3 & & 1 & 1 & & 1 & & & & & \\
\hline & $\begin{array}{ll}11\end{array}$ & $\begin{array}{l}3 \\
3\end{array}$ & & & & & & & & & & 1 & 1 & & 1 & & & & & \\
\hline & 2 & 7 & 2 & & & & & & & & & & & & & & & & & \\
\hline & 4 & 9 & 2 & & 1 & 2 & 1 & 2 & & & 3 & & & & & & & & & \\
\hline & $\begin{array}{ll}11 \\
& 1\end{array}$ & 13 & 1 & 1 & & & 2 & 5 & 1 & 1 & 1 & & & & & & & & & \\
\hline & $\begin{array}{lll}511 \\
\end{array}$ & 8 & 1 & 4 & & 1 & 5 & 2 & & 2 & & & & & & & & & & \\
\hline & & 1 & 1 & 1 & & & & 1 & & & & & & & & 99 & 7 & & & \\
\hline & 1 & 5 & 2 & 2 & & 9 & 6 & 13 & 4 & 10 & 2 & & & & & & & & & \\
\hline
\end{tabular}

were taken from thrush-stones. Sheppard (1951) found that snails in a marked population were not carried to anvils that were only $30 \mathrm{~m}$ distant in woodland; A. J. Gain and J. D. Gurrey (pers. comm.) have found few snails in a marked population in open downland being carried as much as $50 \mathrm{~m}$. Thus the collections gathered by thrushes probably originated from areas of approximately the same size as those within which I collected.

The snails were subsequently scored following the methods of Cain and 
Sheppard (1950, 1954) and Cain and Currey (1963a). The scores for all collections are shown in table 1, omitting minor variants such as punctata (also called interrupta and bandes pâles) since these are not easy to score in some samples of old shells. For some sites, the figures result from a number of collections made at intervals during the 2-year study. Since in no case were repeated collections from the same site significantly different from each other, they have been lumped in table 1 .

In this work only collections with more than four individuals of the species in question have been considered, except where otherwise stated. This lower limit is smaller than is usual in work on Cepaea simply because of the paucity of snails in the district.

The sites of collection have been grouped into five vegetational categories: woodland (mixed deciduous, usually with Quercus as the original, if not the dominant, species), hedgerows, tall herbage (patches of Urtica, Epilobium,

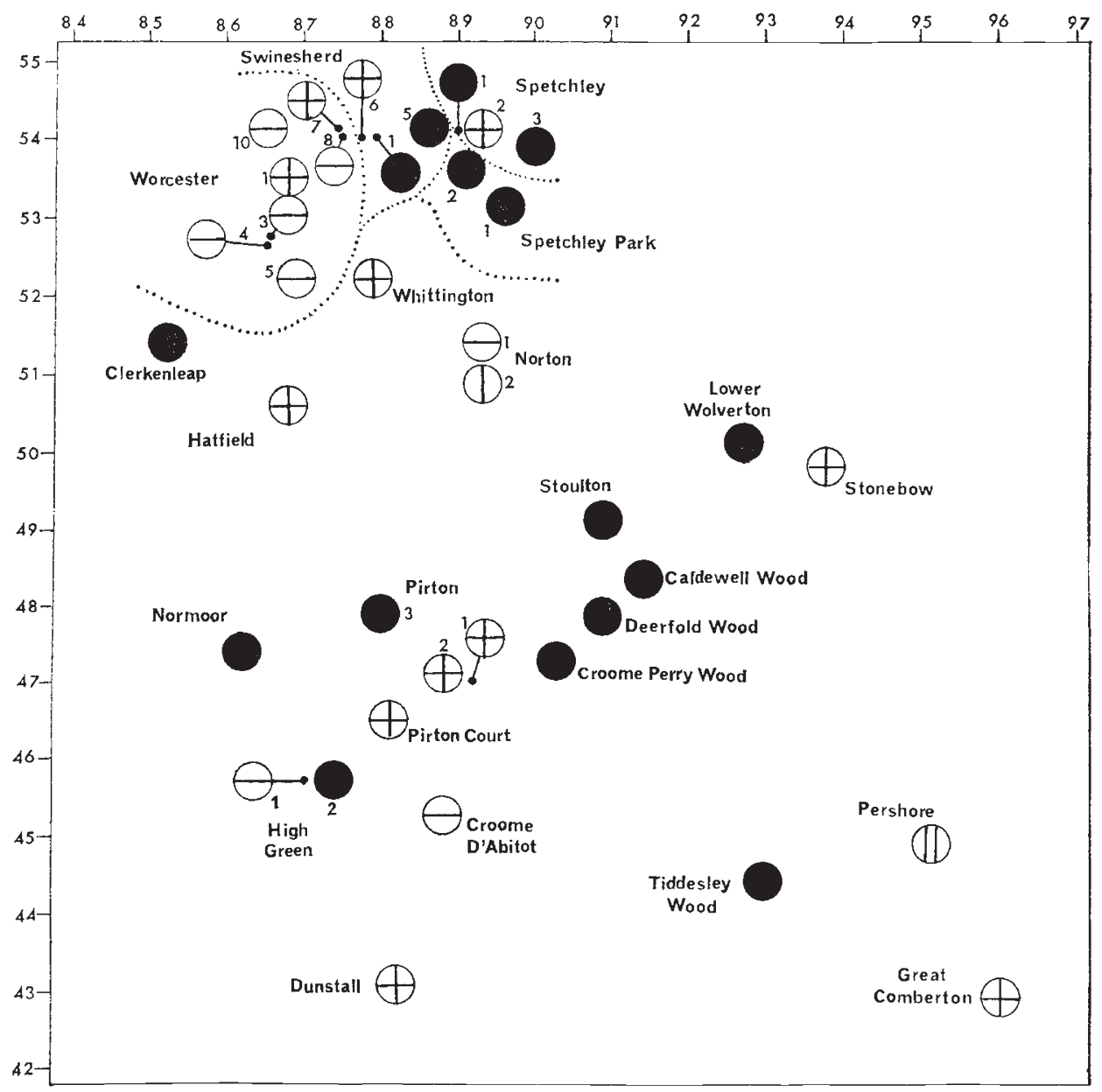

Frg. 1.-Distribution of sampling points in Worcestershire. Filled circles: woods. Crossed circles: hedgerows. Circles with two vertical lines: tall herbage. Circles with one vertical line: long grass. Circles with one horizontal line: rough herbage. Kilometre squares of the national grid are shown at the edges of the diagram. 
etc.), rough herbage (long grass mixed with much broadleaved herbage), grassland (long grass mixed with very little broadleaved herbage: mostly unploughed corners of old leys or railway enbankments). The classification of each site is given in table 1 , together with the height above mean sea-level and whether or not it is within $100 \mathrm{~m}$ of a piece of water large enough to be shown on the 1:63360 Ordnance Survey map (a category including streams wider than about three-quarters of a metre). Both of these features would be expected to influence the micro-climates of the sites. The location and vegetation of each site is shown in fig. 1 .

\section{Ecological Relations of the two species}

There is no evidence of broad geographical differences in the distribution of the two species of Cepaea in Worcestershire. Their relative frequency is not correlated with proximity to water. There are indications, though not statistically significant, that $C$. nermoralis is relatively commoner in woods and that the numbers of the two species in samples are inversely correlated.

C. nemoralis is relatively more frequent at higher altitudes (regression of arcsin transformed relative frequency on height a.s.l.: $P=0 \cdot 021$ ). This is reminiscent of the situation on the Marlborough Downs (Cain and Currey, $1963 a$ ), which is repeated in a less clear fashion on Salisbury Plain (Cain and Currey, 1963b): there, the valleys and bottoms of scarp-slopes have a preponderance of $C$. hortensis and the uplands have $C$. nemoralis only, the difference often being very clear-cut. Cain and Currey believed that $C$. hortensis, being the more northern species, was more able to withstand the ponding of cold air which occurs at night-time in the valleys and Cameron $(1970 a, b, c)$ has provided much physiological, behavioural, and ecological evidence that it is generally better adapted to cooler and damper conditions.

Only two other snails of similar size to Cepaea were found, Helix aspersa Mull. and Arianta arbustorum (L.). The former, considerably bigger than Cepaea, was found at several sites. Arianta, which is superficially much like Cepaea, was found only at Pershore, beside the river; it is known to be adapted to wetter habitats than Cepaea (Cameron, 1970a, b, c).

\section{Polymorphism and background in $C$. nemoralis}

The vegetation categories from which Cepaea was collected fall into two types when considered from the point of view of the visual background they present. On the one hand, woods present a dark but relatively uniform background, composed of areas of leaf-litter. On the other hand, grassland, rough herbage, tall herbage, and hedgerows all present lighter but exceedingly broken backgrounds, composed largely of green or yellow leaves, stems, and grass-blades and the dark shadows between them. For no morphs studied here are there significant differences in frequency between open habitats of different types. There are, however, differences in morph-frequency between open habitats (lumped) and woods. Fig. 2 shows this for yellows and for effectively unbandeds (i.e. shells with at least the upper two bands absent).

The trends for woods to have lower frequencies of yellow and higher frequencies of effectively unbanded than open habitats are highly significant $(\mathrm{P}=0.003$ and 0.002; U-test: Whitney and Mann, 1947). It would appear $33 / 1-B 2$ 


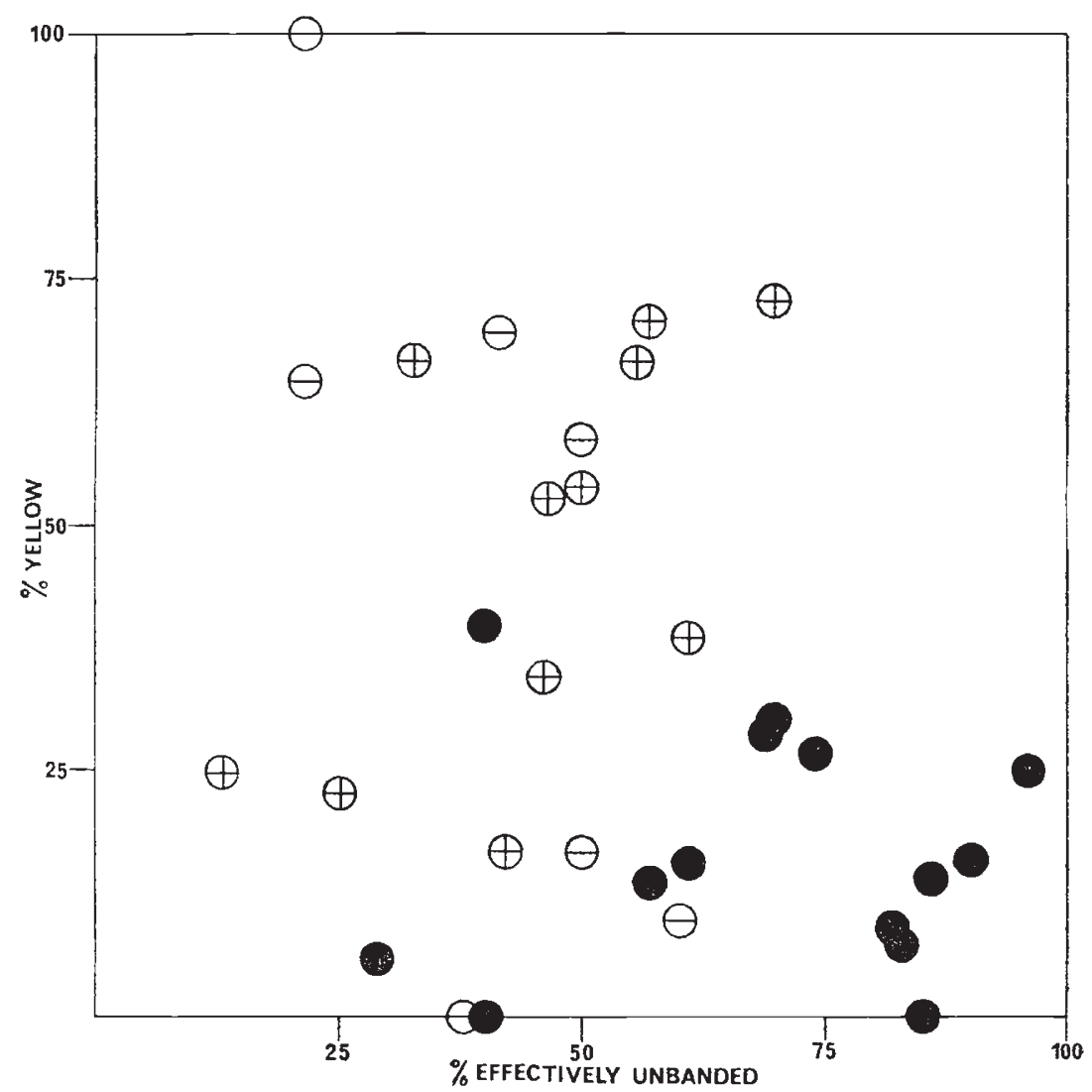

Fig. 2.-Frequencies of yellow and effectively unbanded shells in samples of $C$. nemoralis from various habitats. Symbols asi $n$ fig. 1 .

that yellow snails are relatively less successful in woods than in open habitats, whereas the reverse is true for snails which are effectively unbanded. Considering the nature of the visual backgrounds in woods and open habitats, this could be due to visual selection by predators favouring the more cryptic morphs. The hypothesis that the correlations with habitat are due to correlation of morph-frequency with other variables with which habitat is also correlated, is discussed below.

If visual selection were largely responsible for determining morphfrequencies in the region, one would expect any form of pigmentation which causes the shell to appear darker or less banded to be commoner in woods than in open habitats. In the following account such differences between habitats are examined: even those which are not statistically significant when considered in isolation are discussed, for their combined occurrence may well be significant.

Non-yellow shells may be pink or brown. On average, pinks are 1.5 times and browns 1.7 times commoner in woods than in open habitats ( $P=0.04$ and 0.3 : U-test).

In these collections the effectively unbanded condition is caused by three genetically dominant variants at three unlinked loci. In order of increasing 
unbandedness and epistasis these are listeria (00345), mid-banded (00300), and unbanded. All are commoner in woods than in open habitats-listeria 1.3 times commoner, mid-banded 1.8 times, and unbanded 2.7 times $(\mathrm{P}=0 \cdot 7,0 \cdot 002,0 \cdot 009:$ U-test $)$. Furthermore, it appears that, as one would expect if visual selection were largely responsible for governing morphfrequencies, the difference in frequency between habitats for any one morph is proportional to the number of bands missing in that morph. (Note: by e.g. "frequency of mid-banded" one means the frequency of midbanded in the banded class, a similar convention being used in all cases of epistasis.)

Many of the banded snails show fusions of the bands. One might expect that fusions would be more common in woods than in open habitats, since such fusions would reduce the stripiness of the shell and also make it darker. This is true: both " upper fusions" (those involving the upper two bands) and "lower fusions" are 1.4 times commoner in woods $(P=0.2$ and 0.3$)$.

It will be shown below that absence of bands is much commoner in browns than in pinks, and in pinks than in yellows. Thus one ought to analyse the differences in frequency of unbanded between habitats taking one colour at a time rather than altogether. If this is done, one finds that unbandeds are commoner in woods than in open habitats in all colours, but that the trend is only significant in pinks (yellow, $\mathrm{P}=0.45$; pink $\mathrm{P}=0.0031$; brown, $\mathrm{P}=0.34$ ).

\section{Polymorphism AND BACKGROUND In $C$. hortensis}

The $C$. hortensis found during this study show a much smaller range of variation than the $C$. nemoralis. All except one brown (or perhaps pink) individual from Wadborough, are yellow. As usual, none is mid-banded or listeria. Two hyalozonates represent the only morph found in $C$. hortensis and not in $C$. nemoralis.

The mean frequency of unbandeds is almost identical in woods and open habitats. This is also true in the Oxford region, where the C. hortensis are also mainly yellow (Clarke, 1960). It seems as though the disadvantage which bands give in woods, by producing stripiness, is cancelled, or even outweighed, in yellow shells by the advantage they give by darkening the shell.

As in $C$. nemoralis, fusions are commoner in woods than in open habitats (upper fusions, 1.9 times commoner, $\mathrm{P}=0.003$; lower fusions, 2.1 times commoner, $\mathrm{P}=0.02)$.

\section{POLYMORPhisM AND FURTHER ENVIRONMENTAL VARIABLES}

In neither species does the distribution of morphs show any geographical trends or correlation with proximity to water, but there are apparent correlations with altitude. Eight morphs (yellow, pink, brown, unbanded, mid-banded, listeria, upper fusions, and lower fusions) have been considered in this context in $C$. nemoralis. Since eight possible relations have been examined, I have adjusted the significance tests as Cooper (1969) recommended, taking 0.006 as the 0.05 level. On this criterion even the most pronounced relationship, a positive regression of frequency of listeria on altitude is not significant $(P=0 \cdot 01)$.

The effect of altitude on the frequencies of unbandeds and both types 
of fusions in $C$. hortensis has been examined, so that 0.017 is the significant probability level. Unbandeds are commoner at higher altitudes (fig. 3; regression of arcsin transformed frequency $=15+0.25$ height a.s.l.: $\mathrm{P}=0.01$ ). In contrast, upper fusions are apparently commoner at lower altitudes. However, this correlation is spurious: woodland sites, which have more upper fusions, are generally lower than open sites and partial

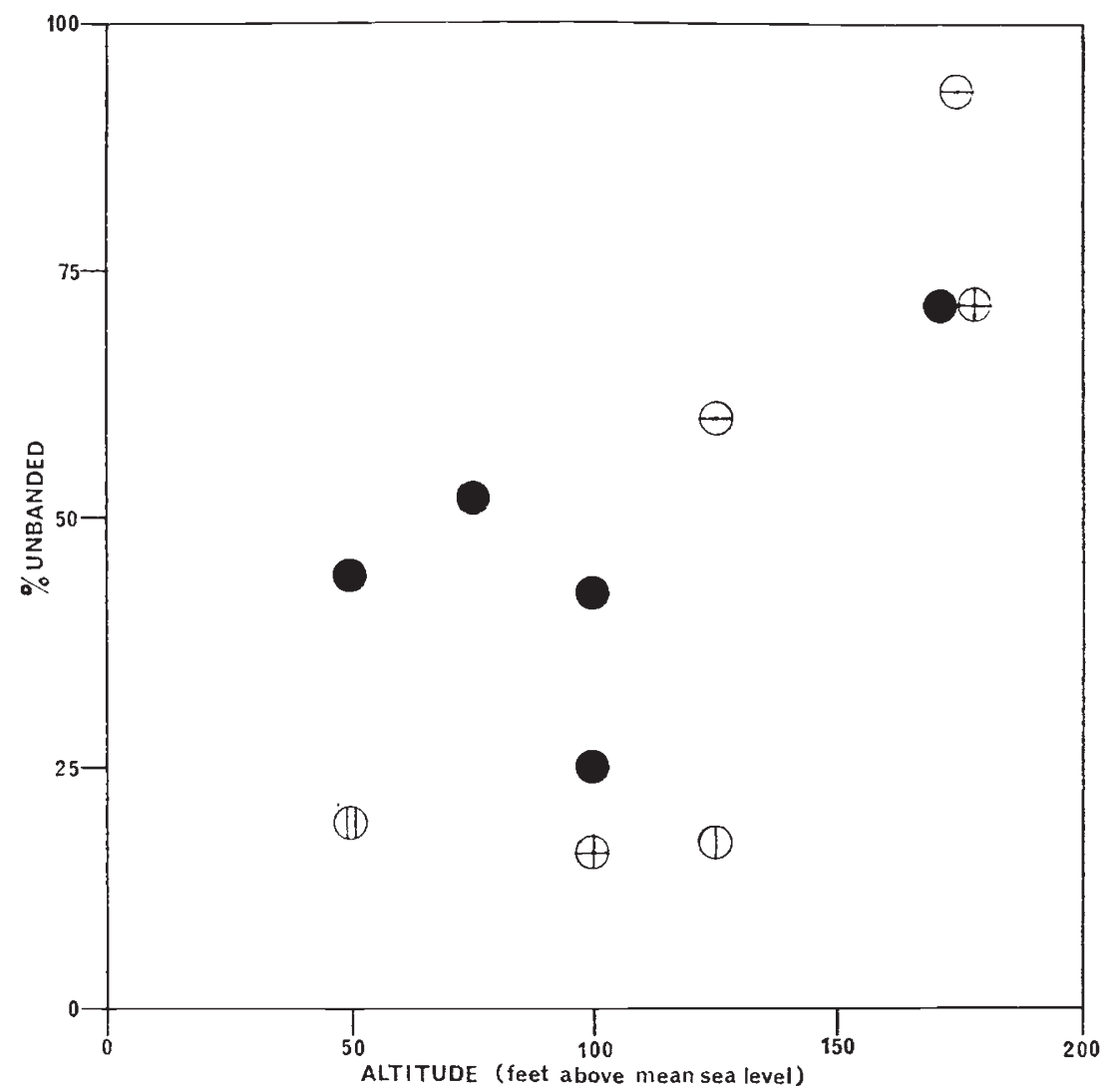

Fig. 3.-Relation of frequency of unbanded shells in samples of $C$. hortensis to altitude. Symbols as in fig. 1 .

regression analysis shows that, while the effect of habitat on frequency of upper fusions is significant $(P=0.004)$, that of altitude is not $(P=0.4)$.

\section{MORPH FREQUENGIES IN MIXED GOLLEGTIONS}

No correlations between the frequencies of the same or corresponding morphs in the two species are detectable. However, there are only five collections with five or more individuals of each species and it is thus impossible to detect any but the most marked correlations.

8. THE EFFECT OF ONE SPECIES ON THE POLYMORPHISM OF THE OTHER

In order to make an objective estimate of the level of polymorphism in a population, I have used a statistic which I call the Index of Polymorphism 
and which is equal to $\left(1-\sum_{i=1}^{m} p_{i}^{2}\right)$, where $p_{i}$ is the frequency of the $i$ th of the $m$ morphs present. This index is equal to the chance of picking individuals of different morphs when one takes two individuals randomly from an infinite population. It is the complement of Simpson's (1949) "measure of concentration ", to which Dr L. M. Cook kindly directed my attention. Simpson pointed out that an unbiased estimator of $\Sigma p_{i}^{2}$ is

$$
\sum n_{i}\left(n_{i}-1\right) / \mathcal{N}(\mathcal{N}-1)
$$

where $n_{i}$ is the number of the $i$ th morph in a sample and $\mathcal{N}$ is the sample size.

The Index of Polymorphism has a possible maximum of $\left(1-\frac{1}{m}\right)$ and a possible minimum of zero. For $C$. nemoralis populations I recognise nine morphs only for the purpose of calculating the Index of Polymorphism, giving a possible maximum of 0.89 . These are three banding patterns (unbanded, mid-banded plus listeria, and five-banded plus its minor modifications) in the three colour classes. To recognise more morphs would add little to the value of the statistic, for other morphs are usually rare and rare morphs

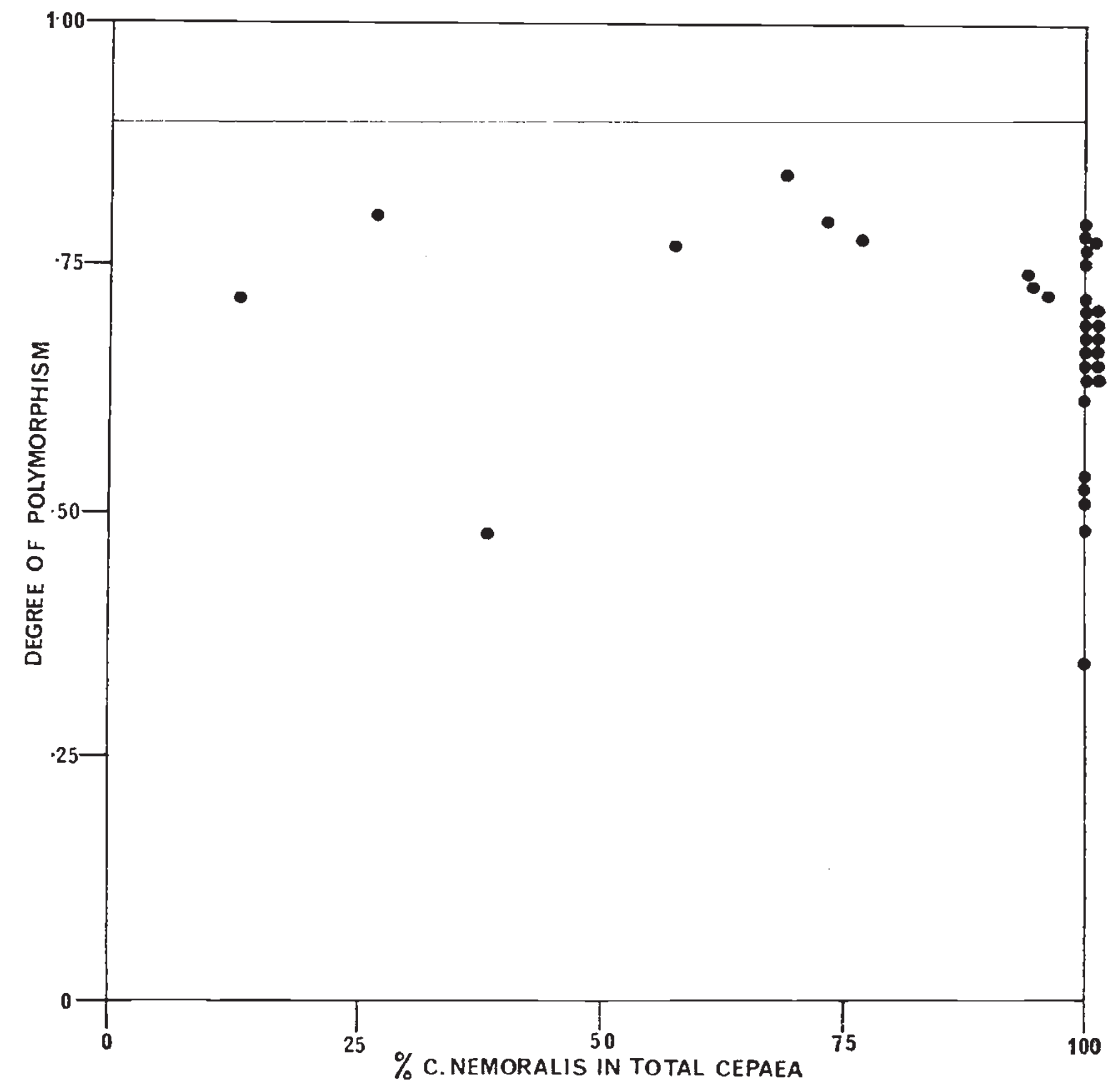

Fig. 4.--Relation of degree of polymorphism of $C$. nemoralis to frequency of $C$. nemoralis in total Cepaea. The maximum degree of polymorphism possible with the number of morphs present is indicated. 
affect the value only slightly. In $C$. hortensis fusions of bands play an important part in the overall variation and so the three banding patterns recognised in calculating the Index of Polymorphism are effectively unbanded (usually comprising truly unbandeds and hyalozonate shells), banded without fusions involving the upper bands, and banded with such fusions. Fusions of upper bands rather than total fusions are considered since this makes discussion of the visual properties of the polymorphism more meaningful and, as far as one may guess, leads to an equally sound measure of genetic diversity.

Examination of the data for both species suggests that populations in woods and hedges may have rather higher Indices of Polymorphism than those from other habitats, but this trend is far from significant statistically. The most marked regular variation in the Index of Polymorphism is that C. nemoralis populations with which $C$. hortensis is also found almost invariably have rather high Indices of Polymorphism, whereas those from which the congener is absent may have high or low Indices of Polymorphism (fig. 4; $\mathbf{P}=0.002$, median test, Fisher's exact method). As fig. 5 shows, it is possible that a similar effect occurs in $C$. hortensis, but the data are too few for one to judge.

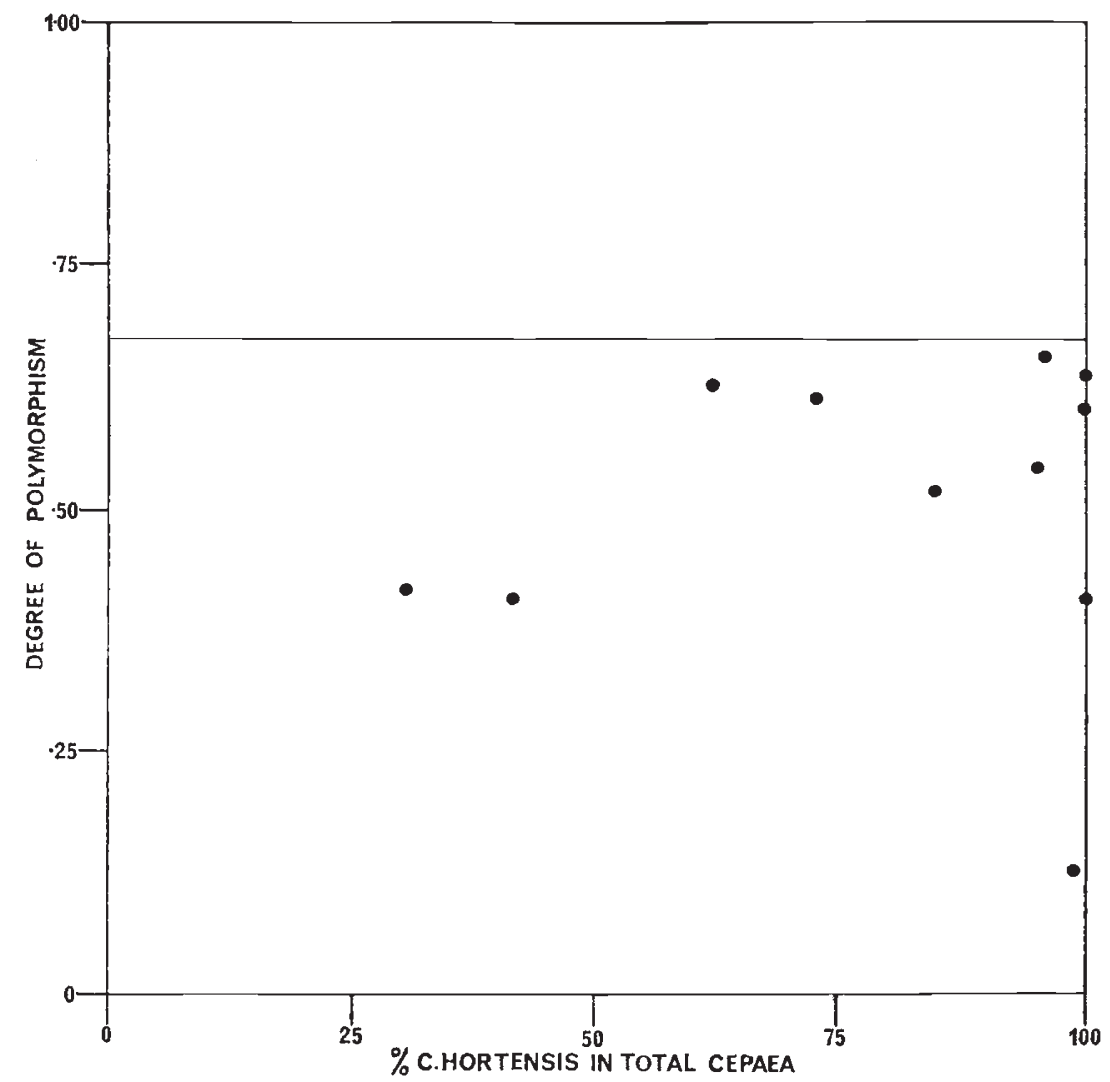

FIG. 5.-Relation of degree of polymorphism of $C$. hortensis to frequency of $C$. hortensis in total Cepaea. The maximum degree of polymorphism possible with the number of morphs present is indicated. 
The frequencies of individual morphs of $C$. nemoralis are not apparently affected by the presence of $C$. hortensis. Thus the effect on the Index of Polymorphism seems to be one operating on the polymorphism as a whole, not an individual loci.

\section{INTERAGTIONS BETWEEN LOCI}

None of the individual collections is large enough for linkage disequilibria, except of the most extreme kind, to be detectable within them. However, counting collections showing disequilibria in each direction, one finds more unbandeds in pinks than in yellows $(10$ samples to two: $\mathrm{P}<0.025)$, more in browns than in yellows (21 to one: $\mathrm{P}<0.001$ ), and more in brown than in pinks ( 24 to zero: $\mathrm{P}<0.001$ ). Thus yellows tend to be the most banded of the colour classes, brown the least. The tendency is manifest in all habitats.

The distribution of the various patterns of banding-mid-banded, listeria, fusions-is not markedly different amongst the three colour classes.

The reduced variation of $C$. hortensis makes the search for linkage disequilibria in this species impossible.

\section{Conclusions}

(i) Visual selection

The most obvious result obtained in this survey is that morph-frequencies in the regions appear to be largely governed by visual selection. It might be argued, as Lamotte (1959) has done, that the visual correlations obtained are, perhaps, spurious: that they are the result of some other selective difference between woods and open habitats. If, for instance, yellow snails are more resistant to strong sunlight, as Lamotte's experiments suggest, there might be a selective differential between woods and open habitats due to this; it would parallel that due to selective predation. Such parallel selective differentials may be responsible for the results obtained.

If visual selection is largely responsible for the determination of morphfrequencies in $C$. nemoralis, then one may expect to find certain differences between colonies in different habitats. They are:

1. Yellows will be more frequent in open habitats than in woods.

2. Pinks will be more frequent in woods.

3. Browns will be more frequent in woods.

4. Unbandeds will be more frequent in woods.

5. Mid-bandeds will be more frequent in woods.

6. The increase in frequency of mid-bandeds in woods will be less than the increase in frequency of unbandeds, since the single band reduces their effective unbandedness.

7. Listeria will be more frequent in woods.

8. The increase in frequency in listeria in woods will be less than that of mid-bandeds.

9. "Upper fusions" will be more frequent in woods.

10. "Lower fusions" will be more frequent in woods.

11. The increase in frequency of lower fusions in woods will be less than that in upper fusions, since they are less often exposed to view. 
Of these predictions, the three concerning colour, being partially interdependent, should perhaps be regarded only as two. All the rest are independent, giving 10 separate predictions. It has been shown that all of them agree with the facts, except the last. Such agreement would be produced by chance only once in 102 times if the basis of prediction were incorrect (the fact that some of the predicted differences are not statistically significant is of no importance-it is the correctness of their direction which matters).

While the regularities in distribution of an individual morph may be explained by non-visual selection paralleling visual selection, that of 10 independent morphs is unlikely to be due to such chance parallels. Furthermore, whereas Lamotte (1959) has pointed out that one would expect an excess of yellows in open habitats as opposed to woods, since yellows are more resistant than the darker morphs to insolation and extreme temperatures, his experiment also showed that five-banded snails are less resistant than unbandeds to such extremes, so that one would expect to find bandeds in woods rather than open habitats. Thus the hypothesis that microclimatic selection, rather than visual selection, is largely responsible for the determination of morph-frequencies in Worcestershire does not agree in its predictions with the facts.

It is more difficult to predict the differences between habitats one would expect in $C$. hortensis. As has been pointed out, one would not expect unbandeds and hyalozonates to be commoner in woods than in open habitats, so failure to find such a difference is not disturbing. One would, however, expect that upper fusions would be commoner in woods, that lower fusions would show a similar tendency, and that the tendency would be less marked for lower fusions than for upper fusions. The first two of these predictions are fulfilled, which suggests that morph-frequencies in $C$. hortensis may also be influenced by visual selection.

\section{((i) Altitudinal correlations}

Two of the three apparent correlations between morph-frequency and altitude may not be real, but that between unbanded in $C$. hortensis and increasing altitude seems genuine. It is interesting that in two other areas of southern England the reverse correlation has been found (Cameron, 1969; Bantock and Noble, 1973). It has been suggested that yellow unbandeds are particularly resistant to night-time frosts, which are intense in valley bottoms in these two areas as in dune-land hollows, where yellow unbanded $C$. hortensis may also tend to be common (Cain, Cameron and Parkin, 1969). The topography of the Worcestershire area is quite different from that of these other areas, but it is nevertheless surprising to find the altitudinal correlation completely reversed.

\section{(iii) Polymorphism and the presence of a congener}

The effect which $C$. hortensis appears to have on the polymorphism of C. nemoralis has several possible interpretations. It may be that the presence of $C$. hortensis indicates poor conditions for $C$. nemoralis and that heterosis is more marked in poor conditions, as seems to be general (Parsons, 1966). It may be that heterosis is more marked under competition from the 
congener. It may be that the presence of $C$. hortensis indicates abundant environmental diversity, conducive to the survival of many morphs. It may be that the polymorphism of Cepaea involves systems of inversions, as in Drosophila, which, following the ideas of Carson (1955, 1958), are selected for in good environments where crossing-over would break up highly adapted gene combinations and are selected against in poor habitats where crossing-over would produce the necessary genetic diversity for dealing with environmental vicissitudes. Finally, apostatic selection (Clarke, 1962a, $b$; Greenwood, 1969; Elton and Greenwood, 1970) could explain the increased diversity in the presence of a similar species. While some of these possibilities may seem inherently more probable than others, there is no way at the moment to choose between them.

\section{(iv) Linkage disequilibria}

Linkage disequilibria between the colour and banding loci, especially the paucity of banded browns, are well known in $C$. nemoralis (Cain and Sheppard, 1950, 1954; Sheppard, 1952; Goodhart, 1956, 1958; Clarke and Murray, 1962; Cain and Currey, 1963a, b; Guerrucci-Henrion, 1966). The significance of these disequilibria has been discussed by Cain and Sheppard (1954) and Cain and Currey (1963a). The universal deficiency of banded browns was put down by the former to non-visual selection of constant direction. They found, however, that the disequilibria involving yellow and pink were not constant in direction: in the Oxford region, where visual selection seems the chief determinant of morph-frequencies, banding was in an excess in yellows in woodland and was deficient in that colour in open habitats. It was suggested that in woods banding was less disadvantageous in yellows than in pinks, due to the strong darkening effect of bands in yellows.

In Worcestershire the situation is different from that in the Oxford region, for there is a deficiency of unbanded yellows in all habitats, just as Cain and Currey (1963b) found in part of Salisbury Plain and GuerrucciHenrion (1966) found in Brittany. It seems possible that in those three regions non-visual selection may be responsible for the disequilibria, as it almost certainly is on the Marlborough Downs, where the direction of the disequilibria shows " area effects" (Cain and Currey, 1963a).

\section{(v) General}

Visual selection is now well established as an effective force acting in populations of $C$. nemoralis and $C$. hortensis in several parts of central England (Cain and Sheppard, 1954; Currey, Arnold and Carter, 1964; this paper). Lamotte (1959), working on C. nemoralis, has discovered correlations with habitat in parts of France and also correlations of regional mean genefrequencies with various climatic factors. Guerrucci-Henrion (1966) has found a correlation between distance from the coast and frequency of yellow in colonies in Brittany; one has suggested climatic factors which may be responsible for producing such correlations. Cain and Currey (1963a) presented evidence, both from geographical distribution over Europe and local distribution over the Marlborough Downs, that in C. nemoralis dark browns are associated with cool conditions. Despite the discovery of these 
regularities in the distribution of various morphs, the French workers, especially, are disturbed by the wide variation of morph-frequencies shown by colonies from similar habitats and geographical positions. This study has shown, on the basis of a few small collections, that within even a small area of countryside both visual and non-visual selection may be operating effectively on populations of Cepaea. In a situation in which some character is affected by a number of variables, one expects a wide variation still to remain in the character even when one of the variables is stabilised. Thus the wide variation in gene-frequencies of Cepaea populations can be explained as the product of several selective forces, in combinations which are unique for each population. The occurrence of demonstrable regularities renders it unlikely that random genetic drift plays more than a minor role in the populations studied.

Acknowledgments.-It is a great pleasure to acknowledge the help and advice given to me during this work by my supervisor, Professor A. J. Cain. I would also like to thank Dr R. A. D. Cameron and an anonymous referee who made useful comments on an earlier draft of this paper and Professor Cain and R. Dennell for the facilities with which I have been provided in the Manchester University Department of Zoology.

During this work, I held the Philip Buckle Scholarship in Agricultural Zoology and a Science Research Council Studentship.

\section{REFERENCES}

BANTOCK, C. R., AND NOBLE, K. 1973. Variation with altitude and habitat in Cepaea hortensis (Müll.). Zool. F. Linn. Soc., 53, 237-252.

CAin, A. J., CAMERON, R. A. D., AND PARkin, D. T. 1969. Ecology and variation of some helicid snails in Northern Scotland. Proc. malac. Soc. Lond., 38, 269-299.

cain, A. J., And currey, J. D. 1963a. Area effects in Cepaea. Phil. Trans. Roy. Soc. Lond., B, $246,1-81$.

CAIN, A. J., AND CURREY, J. D. 1963b. Area effects in Cepeae on the Larkhill Artillery Ranges, Salisbury Plain. 7. Linn. Soc. Lond. (Zool.), 45, 1-15.

CAIN, A. J., AND sheppard, P. M. 1950. Selection in the polymorphic land snail Cepaea nemoralis. Heredity, 4, 275-294.

CAIn, A. J., AND Sheppard, P. M. 1954. Natural selection in Cepaea. Genetics, 39, 89-116.

CAMERON, R. A. D. 1969. The distribution and variation of three species of land snail near Rickmansworth, Hertfordshire. 7. Linn. Soc. (Zool.), 48, 83-111.

CAMERON, R. A. D. 1970a. The survival weight-loss and behaviour of three species of land snail in conditions of low humidity. 7. Zool. Lond., 160, 143-157.

CAMERON, R. A. D. 1970b. The effect of temperature on the activity of three species of Helicid snail (Mollusca: Gastropoda). F. Zool. Lond., 162, 303-315.

CAMERON, R. A. D. 1970c. Differences in distribution of three species of helicid snail in the limestone district of Derbyshire. Proc. Roy. Soc. B, 176, 131-159.

CARsON, H. L. 1955. The genetics of marginal populations of Drosophila. Cold Spring Harbor Symp. Quant. Biol., 20, 276-287.

CARson, H. L. 1958. The population genetics of Drosophila robusta. Adv. Genetics, 9, 1-40.

CLARKE, B. c. 1960. Divergent effects of natural selection on two closely-related polymorphic snails. Heredity, 14, 423-433.

CLARKE, B. C. 1962a. Natural selection in mixed populations of the polymorphic snails. Heredity, 17, 319-345.

CLARKE, B. C. 1962b. Balanced polymorphism and the diversity of sympatric species. In Taxonomy and Geography, ed. D. Nichols, Syst. Ass. Pub. No. 4.

CLARKE, B. C., AND MURRAY, J. J. 1962. Changes of gene frequency in Cepaea nemoralis (L.). Heredity, $17,445-465$.

COOPER, D. W. 1969. The significance level in multiple tests made simultaneously. Heredity, $23,614-617$.

CURREY, J. D., ARNOLD, R. W., AND CARTER, M. A. 1964. Further examples of variation of populations of Cepaea nemoralis with habitat. Evolution, 18, 111-117. 
elton, R. A., AND GReEnwood, J. J. D. 1970. Exploring apostatic selection. Heredity, 25, 629-633.

GOODhart, c. B. 1956. Genetic stability in populations of the polymorphic snail, Cepaea nemoralis. Proc. Linn. Soc. Lond., 167, 50-67.

Goodhart, c. B. 1958. Genetic stability in the snail Cepaea nemoralis (L.): a further example. Proc. Linn. Soc. Lond., 169, 163-167.

GREENWOOD, J. J. D. 1969. Apostatic selection and population density. Heredity, 24, 157-161. GUERRUCCi-HENRION, M. A. 1966. Recherches sur les populations naturelles de Cepaea nemoralis en Bretagne. Arch. Zool. Exp. Gen., 107, 369-417.

гамотте, м. 1954. Sur le determinisme génétique du polymorphisms, chez Cepaea nemoralis L. C.R. Acad. Sci., 239, 365-367.

LAmotтE, м. 1959. Polymorphism of natural populations of Cepaea nemoralis. Cold Spring Harbor Symp. Quant. Biol., 24, 65-86.

PARsons, P. A. 1966. The genotypic control of longevity in Drosophila melanogaster under two environmental regions. Aust. F. Biol. Sci., 19, 587-591.

SHEPPARD, P. M. 1951. Fluctuations in the selective value of certain phenotypes in the polymorphic land snail Cepaea nemoralis (L.). Heredity, 5, 125-134.

SHEPPARD, P. M. 1952. Natural selection in two colonies of the polymorphic land snail Cepaea nemoralis. Heredity, 6, 233-238.

simpson, E. H. 1949. Measurement of diversity. Nature, 163, 688.

WHITNEY, D. R., AND MANN, H. B. 1947. On a test of whether one or two random variables is stochastically larger than the other. Ann. Math. Statist., 18, 50-60. 